\title{
Study on the Hatching Characteristics and Diet of the Stick Insect, Baculum elongatum (Phasmida:Phasmatidae) for Artificial Mass Rearing
}

Jin Gu Lee ${ }^{\mathrm{a} *}$, Hee Dong Kimª, Chang Sung Kang ${ }^{\mathrm{a}}$, Ae Gyeong Seo ${ }^{\mathrm{a}}$, Sang Hyun Lee ${ }^{\mathrm{c}}$, Young Kyu Park ${ }^{\mathrm{d}}$, and Young Bo Lee

${ }^{a}$ Gyeonggi-do Agricultural Research and Extension Services, Hwaseong 445-972, Korea

${ }^{b}$ National Academy of Agricultural Science, Suwon 441-100, Korea

${ }^{c}$ Sunyou. Co. Ltd., Namyangju 472-851, Korea

${ }^{b}$ Korea Beneficial Insects Lab. Co. Ltd. Anseong 456-913, Korea

\section{Abstract}

Baculum elongatum has several peculiarities such as parthenogenesis, unique external features, changing body color, and dropping oviposition, which makes it a potential economically useful insect. Oviposition was performed by females without fertilization by the sperm of males. The oviposition period was $42.2 \pm 22.7$ days and the number of eggs per female was $109.5 \pm 70.5$ eggs. The hatch rate was $73.3 \%$ at $25^{\circ} \mathrm{C}$ and $66.7 \%$ after low temperature treatment ( $8^{\circ} \mathrm{C}$ for 60 days). In nature, B. elongatum overwinters as an egg, but it can be assumed from the results that cold temperatures were not required for hatching. The hatch rate was $98.2 \%$ in the treatment using floral foam, fermented sawdust, and leaves. The developmental period was $100.9 \pm 4.2$ days for eggs, $55.3 \pm 4.6$ days for nymphs, and $49.7 \pm 16.0$ days for adults. The length of the eggs was $0.33 \pm 0.0 \mathrm{~cm}$ and the lengths of the nymphs were clearly distinguishable according to the instar stage. Clover(Trifolium repens) was an excellent diet as it was similar to the host plant and could be used as an alternative diet. The rate of reaching adulthood for the insects was $66.7 \%$ on an artificial diet containing $25 \%$ acacia leaves. For sustainable mass rearing of nymphs or adults of B. elongatum, a natural diet could be used such as acacia (Robinia pseudoacacia), white oak (Quercus aliena), chestnut (Castanea crenata var. dulcis), and bush clover (Lespedeza bicolor), or an alternative diet such as clover or artificial diet.

(c) 2013 The Korean Society of Sericultural Sciences

Int. J. Indust. Entomol. 26(1), 61-66 (2013)

Received: Accepted:

12 March 2012

27 March 2013
Keywords: Stick insect, Baculum elongatum, Economic insect

\section{Introduction}

Insects can provide economic resources as pets, pollen vectors, natural enemies, food, or medical uses. Allomyrina dichotoma and Dorcus titanus are gorgeous beetles and popular pet insects in Korea,

\section{*Correspondence :}

Jin Gu Lee

Gyeonggi-do Agricultural Research and Extension Services, Hwaseong 445-972, Korea

Tel: +82-31-229-6192 / FAX: +82-31-834-3107

E-mail: seamt@gg.go.kr

http://dx.doi.org/10.7852/ijie.2013.26.1.061

C 2013 The Korean Society of Sericultural Sciences 
but industrial insect farmers require new, diverse pet insects as a source of income.

Stick insects are terrestrial phytophagous insects found in nearly all temperate and tropical ecosystems. Over 3000 species exist in the world, including 5 species in Korea. To avoid predators, they either play dead or try to scare the predator with a startle display such as leg kicking or spastic motion. Some species can purposely lose some of their legs to aid their escape from a predator's grasp and can regenerate the lost limbs during successive molts; further, these species are popular as pets and as displays at zoological gardens (John, 2008). Their body color can change depending on the environmental conditions; in Carausius morosus, the body pigmentation can be affected by visual stimulation of its compound eyes (Detlef, 1977). Much research has been carried out on their oviposition behavior, maturation divisions of parthenogenesis, preying by spiders, and leg movements (Carlberg, 1984; Eva and Ulrich, 1985; Pijnacker, 1966; Wolfgang, 1990).

Baculum elongatum has a long, thin shape that resembles a twig, propagates by parthenogenesis, changes body color, and drops eggs, all of which suggests its potential in the commercial market, especially as an educational pet insect.

Thus, this study was carried out to determine the best hatching environment and an alternative or artificial diet for rearing $B$. elongatum to be developed as a commercial and educational pet insect.

\section{Materials and Methods}

Baculum elongatum were collected from Mt. Mubong in Hwaseong, Gyeonggi Province, in 2010, and successively reared to the $4^{\text {th }}$ generation in a rearing room. The diets used for rearing included fresh leaves from acacia (Robinia pseudoacacia), white oak (Quercus aliena), chestnut (Castanea crenata var. dulcis), bush clover (Lespedeza bicolor), and clover (Trifolium repens).

\section{Hatching characteristics}

To investigate the characteristics of oviposition of $B$. elongatum, nymphs were reared individually in rearing cage $(20 \times 15 \times 15 \mathrm{~cm})$ set in a rearing room maintained at $25 \pm 1{ }^{\circ} \mathrm{C}$ and $65 \pm 5 \%$ relative humidity under a photoperiod of light-dark (LD) 16:8 h. Observations were made every day to record the day of molting for adults, the day of first and last oviposition, and the number of oviposited eggs.

To investigate the hatch rate of $B$. elongatum after a period of exposure to cold temperatures, 16 treatments were conducted. The rearing cages (30 $\times 20 \times 20 \mathrm{~cm}$ ) were half-filled with soil, and the eggs were spread on the soil and covered with fallen leaves. The hatching of eggs of B. elongatum was very difficult; hence, in this study, we considered the environmental conditions observed in the natural habitat of B. elongatum. Five cages were placed in each of 3 growth chambers set to a temperature of 0 , 4 , or $8^{\circ} \mathrm{C}$ and after $30,60,90,120$ or 150 days 1 cage from each chamber was placed in the rearing room at $25^{\circ} \mathrm{C}$. One cage was retained in the rearing room at $25^{\circ} \mathrm{C}$. The eggs were checked every day to see if they had hatched.

To investigate the hatch rate of $B$. elongatum under different hatching conditions, 4 treatments were conducted. In the $1^{\text {st }}$ treatment, rearing cage $(30 \times 20 \times 20 \mathrm{~cm})$ were half-filled using fermented sawdust, which is generally used to rear Allomyrina dichotoma, and the eggs were spread on the sawdust. The $2^{\text {nd }}$ treatment was similar to $1^{\text {st }}$ treatment, except that the eggs were covered using fallen leaves. The $3^{\text {rd }}$ treatment was similar to the $1^{\text {st }}$ except that the floral foam, which is commonly used for flower arrangement, was embedded in the sawdust. The $4^{\text {th }}$ treatment was similar to the $3^{\text {rd }}$ except that the eggs covered using fallen leaves. The cages were placed in the rearing room at $25 \pm 1{ }^{\circ} \mathrm{C}$ and $65 \pm 5 \%$ relative humidity under a photoperiod of light-dark (LD) 16:8 $h$. The eggs were checked every day to see if they had hatched. 


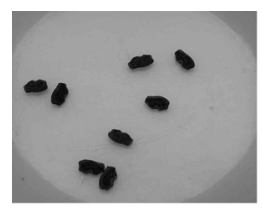

Egg

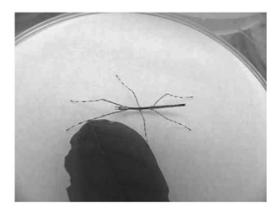

Nymph

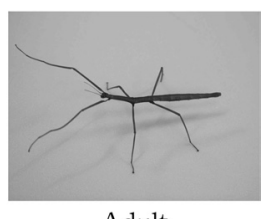

Adult
Fig. 1. Developmental stages of Baculum elongatum.

To investigate the hatch rate of $B$. elongatum under different temperatures, the eggs treated using the methods from the $3^{\text {rd }}$ treatment of previous experiment were put on a weighing dish $(3 \times 3 \mathrm{~cm})$. One cage each was placed in rearing rooms set at 20, 22.5, 25, 27.5 , or $30^{\circ} \mathrm{C}$ and $65 \pm 5 \%$ relative humidity under a photoperiod of light-dark (LD) 16:8 h. The eggs were checked every day to see if they had hatched.

To investigate the developmental period and body length of insects of each stage, individual nymphs and adults were reared in rearing cages $(20 \times 15 \times$ $15 \mathrm{~cm})$ at $25 \pm 1{ }^{\circ} \mathrm{C}$ and $65 \pm 5 \%$ relative humidity under a photoperiod of light-dark (LD) 16:8 h. Insects were checked every day for hatching molting and mortality. The length of eggs and nymphs were measured under a stereomicroscope and using a ruler, respectively.

\section{Alternative and artificial diet}

To select an alternative diet, leaves of several plants were tested such as acacia, white oak, chestnut, bush clover, clover, grape, pepper, gyeolmyeong-ja, rice, corn, adlay, and bean. A nymph was reared on a diet of each test plant in the rearing room for 3 days. If the nymph ate the plant, then the test was continued. This was to determine whether the insects that consumed the test plant leaves developed to the next stage.

To develop an artificial diet, acacia leaf powder was used as the main host plant source and agar was used as the coagulating agent. Fresh acacia leaves were dried using a drier at $50^{\circ} \mathrm{C}$ for $48 \mathrm{~h}$ and were ground into powder by using electric grinder. After boiling in $100 \mathrm{~mL}$ distilled water, 1, 2, of $3 \mathrm{~g}$ of agar corresponding to 1,2 , or $3 \%$ treatments, respectively were added and boiled for further $10 \mathrm{~min}$. Leaf powder in the amount of $5,10,15,20$, of $25 \mathrm{~g}$ corresponding to $5,10,15,20$, or $25 \%$ treatments, respectively, were added and mixed along with several additives, including malt (14 g), yeast (7.5 g), vitamins (1.9 g), sorbic acid (0.3 g), salt mixture (1 g), ascorbic acid (1.9 g) and MPH (0.6 g).

\section{Results and Discussion}

\section{Hatching characteristics}

The pre-oviposition and post-oviposition periods were $14.5 \pm 2.2$ and $1.4 \pm 2.0$ days, respectively, and their deviations were not high. The oviposition period and the number of eggs per female were $42.2 \pm$ 22.7 days and $109.5 \pm 70.5$, respectively, with high deviations(Table 1). These results differed from that shown in a study where the oviposition period and number of eggs per female were 54.23 days and 60, respectively (Park et al., 2003).

The hatch rates of $B$. elongatum after 30 and 60 days at $8^{\circ} \mathrm{C}$ was 70.0 and $67.7 \%$, respectively, and $73.3 \%$ at $25^{\circ} \mathrm{C}$. In nature, B. elongatum overwinters as an egg, but cold temperatures were not required for hatching (Table 2). The hatch rate of $B$.

Table 1. Characteristics of oviposition of Baculum elongatum

\begin{tabular}{|c|c|c|c|}
\hline $\begin{array}{c}\text { Pre-oviposition period } \\
\text { (days } \pm \text { SD) }\end{array}$ & $\begin{array}{c}\text { Oviposition period } \\
\text { (days } \pm \text { SD) }\end{array}$ & $\begin{array}{c}\text { Post-oviposition period } \\
\text { (days } \pm \text { SD) }\end{array}$ & $\begin{array}{c}\text { Number of eggs } \\
\text { (eggs/female } \pm \text { SD) }\end{array}$ \\
\hline $14.5 \pm 2.2$ & $42.2 \pm 22.7$ & $1.4 \pm 2.0$ & $109.5 \pm 70.5$ \\
\hline
\end{tabular}

* Nymphs $(\mathrm{n}=30)$ were reared in a rearing room at $25 \pm 1^{\circ} \mathrm{C}$ and $65 \pm 5 \%$ relative humidity under a photoperiod of light-dark (LD) $16: 8 \mathrm{~h}$. 
Table 2. Hatch rate $(\%)$ of Baculum elongatum after exposure to different durations of cold temperature

\begin{tabular}{|c|c|c|c|c|c|c|}
\hline Temperature ( & 0 & 30 & 60 & 90 & 120 & 150 \\
\hline 0 & \multirow{3}{*}{73.3} & 63.3 & 60.0 & 30.0 & 26.7 & 0 \\
\hline 4 & & 50.0 & 46.7 & 53.3 & 13.3 & 10.0 \\
\hline 8 & & 70.0 & 66.7 & 10.0 & 6.7 & 0 \\
\hline
\end{tabular}

* For each treatment, $30 \times 20 \times 20 \mathrm{~cm}$ cage with soil, eggs $(\mathrm{n}=30)$, and fallen leaves was used. After the cold temperature treatment, each cage was placed in a rearing room maintained at $25 \pm 1^{\circ} \mathrm{C}$ and $65 \pm 5 \%$ relative humidity under a photoperiod of light-dark (LD) $16: 8 \mathrm{~h}$.

Table 3. Hatch rate of Baculum elongatum under different hatching conditions

\begin{tabular}{|c|c|c|}
\hline Treatments & n & Hatch rate $(\%)$ \\
\hline Fermented sawdust and Eggs & 50 & 70.0 \\
\hline Fermented sawdust, Eggs, and Leaves & 50 & 92.0 \\
\hline Floral foam, Fermented sawdust, and Eggs & 50 & 86.0 \\
\hline Floral foam, Fermented sawdust, Eggs, and Leaves & 55 & 98.2 \\
\hline
\end{tabular}

* For each treatment, $30 \times 20 \times 20 \mathrm{~cm}$ cage was placed in a rearing room maintained at $25 \pm 1^{\circ} \mathrm{C}$ and $65 \pm 5 \%$ relative humidity under a photoperiod of light-dark (LD) 16:8 h.

Table 4. Hatch rate of Baculum elongatum under different temperatures

\begin{tabular}{|c|c|c|c|c|c|c|}
\hline Temperature $\left({ }^{\circ} \mathrm{C}\right)$ & $\mathrm{n}$ & 20 & 22.5 & 25 & 27.5 & 30 \\
\hline Hatch rate $(\%)$ & $50-60$ & 85.0 & 83.3 & 80.0 & 18.3 & 0 \\
\hline
\end{tabular}

* For each treatment, $30 \times 20 \times 20 \mathrm{~cm}$ cage with floral foam, fermented sawdust, egg dish, and eggs was placed in a rearing room maintained at 65 $\pm 5 \%$ relative humidity under a photoperiod of light-dark (LD) $16: 8 \mathrm{~h}$.

elongatum was $98.2 \%$ in the treatment comprising floral foam, fermented sawdust, and leaves and $92.0 \%$ in the treatment comprising the fermented sawdust, leaves (Table 3). The optimal temperature for hatching was approximately $20-25^{\circ} \mathrm{C}$. In the 27.5 and $30^{\circ} \mathrm{C}$ treatments, the hatch rate was very low (Table 4).

The developmental period of $B$. elongatum was $100.9 \pm 4.2$ days as an egg, $55.3 \pm 4.6$ days as a nymph and $49.7 \pm 16.0$ days as an adult. Further, a previous study showed that $B$. elongatum has 5 nymph stages(Park et al., 2003), but the nymphs in this study showed $5(62.9 \%)$ or $6(37.1 \%)$ stages. Nymph lengths were clearly separable according to the instar and the deviation in length was very low (Table 5). For the hatching of $B$. elongatum eggs, humidity is very important, and floral foam can help maintain the moisture. Kim et al. (2011) reported that when hatching the Emma field cricket, Teleogryllus emma, floral foam was moistened frequently with water so that the hatching of the eggs would not be affected by moisture loss. 
Table 5. Developmental period and body length of each stage of Baculum elongatum

\begin{tabular}{|c|c|c|c|c|c|c|c|c|c|}
\hline \multirow[b]{2}{*}{ Stage } & \multirow[b]{2}{*}{ Egg } & \multicolumn{7}{|c|}{ Nymph } & \multirow[b]{2}{*}{ Adult } \\
\hline & & $\begin{array}{c}1^{\text {st }} \\
\text { instar }\end{array}$ & $\begin{array}{l}2^{\text {nd }} \\
\text { instar }\end{array}$ & $\begin{array}{l}3^{\text {rd }} \\
\text { instar }\end{array}$ & $\begin{array}{c}4^{\text {th }} \\
\text { instar }\end{array}$ & $\begin{array}{l}5^{\text {th }} \\
\text { instar }\end{array}$ & $\begin{array}{l}6^{\text {ths }} \\
\text { instar }\end{array}$ & Total & \\
\hline $\begin{array}{l}\text { Developmental period } \\
\quad(\text { days } \pm S D)\end{array}$ & $\begin{array}{l}100.9 \\
\pm 4.2\end{array}$ & $\begin{array}{r}9.9 \\
\pm 1.6\end{array}$ & $\begin{array}{c}7.3 \\
\pm 1.0\end{array}$ & $\begin{array}{c}7.7 \\
\pm 1.3\end{array}$ & $\begin{array}{r}10.3 \\
\pm 1.3\end{array}$ & $\begin{array}{r}14.7 \\
\pm 3.2\end{array}$ & $\begin{array}{r}13.5 \\
\pm 1.8\end{array}$ & $\begin{array}{l}55.3 \\
\pm 4.6\end{array}$ & $\begin{array}{c}49.7 \\
\pm 16.0\end{array}$ \\
\hline $\begin{array}{l}\text { Body length } \\
(\mathrm{cm} \pm \mathrm{SD})\end{array}$ & $\begin{array}{l}0.33 \\
\pm 0.0\end{array}$ & $\begin{array}{r}1.6 \\
\pm 0.2\end{array}$ & $\begin{array}{c}2.4 \\
\pm 0.1\end{array}$ & $\begin{array}{c}3.4 \\
\pm 0.1\end{array}$ & $\begin{array}{r}4.5 \\
\pm 0.1\end{array}$ & $\begin{array}{c}5.8 \\
\pm 0.4\end{array}$ & $\begin{array}{c}6.6 \\
\pm 0.3\end{array}$ & - & $\begin{array}{r}7.5 \\
\pm 0.4\end{array}$ \\
\hline
\end{tabular}

* Baculum elongatum $(n=35)$ were reared in the rearing room maintained at $25 \pm 1{ }^{\circ} \mathrm{C}$ and $65 \pm 5 \%$ relative humidity under a photoperiod of light-dark (LD) $16: 8$ h. $5^{\text {th }}$ instar: $62.9 \%{ }^{\circ} 6^{\text {th }}$ instar: $37.1 \%$

Table 6. Potential of alternative diet plants for Baculum elongatum

\begin{tabular}{|c|c|}
\hline Potential $^{\cdot}$ & Plants (Leaves) \\
\hline 5 & $\begin{array}{c}\text { Acacia, White oak, Chestnut, Bush } \\
\text { clover, Clover }\end{array}$ \\
\hline 3 & Grape, Pepper, Gyeol-myeong-ja \\
\hline 1 & Rice, Corn, Adlay, Bean \\
\hline $\begin{array}{l}\text { 5: Very high (as host plant); 3: Consumed but no normal growth; 1: } \\
\text { Not consumed }\end{array}$ \\
\hline
\end{tabular}

\section{Alternative and artificial diet}

B. elongatum did not feed on rice, corn, adlay, or bean leaves. While the insects ate grape, pepper, and gyeol-myeong-ja leaves, they did not develop to the next stage. Clover was an excellent diet, as was acacia, white oak, chestnut, and bush clover (Table 6). It is known that acacia, white oak, chestnut, and bush clover are the host plants of B. elongatum. The host plants are deciduous woody plants, so it is difficult to harvest them for the diet during the winter in Korea. Clover, however, is an herbaceous plant and easy to manage in a green-house; hence, it could be promising as an alternative diet. Peanuts and beans have been shown as potential alternative diets for rearing Poecilocoris lewisi (Kim and Seol, 2003) and it is important that the alternative diet should be obtained cheaper and easier than the natural host plant.

The rate of reaching adulthood for B. elongatum was $66.7 \%$ by using an artificial diet of $25 \%$ acacia leaf powder and $1 \%$ agar and was $0 \%$ by using an artificial diet of approximately $5-10 \%$ acacia leaf powder (Table 7). Much research has been carried

Table 7. Rate of Baculum elongatum reaching adulthood when fed artificial diets of different media and leaf powder densities

\begin{tabular}{|c|c|c|c|c|c|c|}
\hline \multicolumn{2}{|c|}{ Host plant } & \multicolumn{6}{|c|}{ Leaf powder of acacia } \\
\cline { 3 - 7 } & & $5 \%$ & $10 \%$ & $15 \%$ & $20 \%$ & $25 \%$ \\
\hline \multirow{3}{*}{ Agar } & $1 \%$ & 0 & 0 & 6.7 & 40.0 & 66.7 \\
\cline { 2 - 7 } & $2 \%$ & 0 & 0 & 20.0 & 40.0 & 33.3 \\
\cline { 2 - 7 } & $3 \%$ & 0 & 0 & 20.0 & 6.7 & 46.7 \\
\hline
\end{tabular}

\footnotetext{
* Baculum elongatum ( $\mathrm{n}=30$ ) were reared on an artificial diet in the rearing room at $25 \pm 1{ }^{\circ} \mathrm{C}$ and $65 \pm 5 \%$ relative humidity under a photoperiod of light-dark (LD) 16:8 h. The \% was measured as $\mathrm{g} / 100 \mathrm{~mL}$ of distilled water
} 
out to develope an artificial diet for the harmful insect or industrial insect, for example, Matsumuraeses phaseoli, Teleogryllus emma(Jung et al., 2007; Kim et al., 2007), and artificial diets can be used for sustainable rearing during seasons when it is difficult to obtain the host plant or other food.

The best results for hatching the eggs of $B$. elongatum, was by using a rearing cage $(30 \times 20 \times$ $20 \mathrm{~cm}$ ) set with fermented sawdust, and leaves or floral foam, fermented sawdust, and leaves and placed in a rearing room maintained at approximately 20$25^{\circ} \mathrm{C}$ and $65 \pm 5 \%$ relative humidity. To rear nymphs and adults of $B$. elongatum, natural diet such as acacia, white oak, chestnut, or bush clover leaves, or an alternative diet such as clover or an artificial diet can be used.

\section{Acknowledgement}

This study was carried out with the support of the Research Program for Agricultural Science \& Technology Development, National Academy of Agricultural Science, Rural Development Administration, Republic of Korea.

\section{References}

Detlef Btickmann (1977) Morphological Colour Change: Stage Independent, Optically Induced Ommochrome Synthesis in Larvae of the Stick Insect, Carausius morosus Br. J comp Physiol. 115, 185-193.

Eva Foth and Ulrich Bfissler (1985) Leg Movements of Stick Insects Walking with Five Legs on a Treadwheel and with One Leg on a Motor-Driven Belt, Biol Cybern.
51, 319-324.

John L. Capinera (2008) Encyclopedia of Entomology, Springer Science+Business Media.

Jung JK, Seo BY, Park JH, Moon JK, Choi BS, Lee YH (2007) Developmental Characteristics of Soybean Podworm, Matsumuraeses phaseoli (Lepidoptera: Tortricidae) and Legume Pod Borer, Maruca vitrata (Lepidoptera: Pyralidae) on Semi-synthetic Artificial Diets, Korean, J Appl Entomol 46(3), 393-399.

Kim NJ and Seol KY (2003) Artificial Rearing of Red-striped Golden Stink Bug, Poecilocoris lewisi (Hemiptera : Scutelleridae) on Peanut : Developmental Characteristics, Host Plant and Oviposition Preference, Korean, J Appl Entomol 42(2), 133-138.

Kim NJ, Hong SJ, Kim SH (2011) Diapause Characteristics of the Emma Field Cricket, Teleogryllus emma. Int $\mathrm{J}$ Indust Entomol 23(2), 207-213.

Kim NJ, Hong SJ, Seol KY, Kim SH, Ahn NH, Park HC, Lee YB, Kim MA (2007) Artificial Diet for Mass Rearing the Emma Field Cricket, Teleogryllus emma (Orthoptera: Gryllidae) Int J Indust Entomol 15(2), 157160.

L. P. Pijnacker (1966) The maturation divisions of the parthenogenetic stick insect Carausius morosus $\mathrm{Br}$. (Orthoptera, Phasmidae), Chromosoma (Berl.) 19, 99112.

Park YS, Kwon TS, Kim JK, Kim CS, Park JD (2003) Effect of Temperatures on the Development of the Stick Insect, Baculum elongatum (Phasmida: Phasmatidae) and the Life Cycle. J Kor For Soc 92(1), 62-70.

U. Carlberg (1984) Oviposition behavior in the Australian stick insect Extatosoma tiaratum. Experientia 40, BirkhSauser Verlag, CH-4010 Basel/Switzerland.

Wolfgang Nentwig (1990) Stick insects (Phasmida) as prey of spiders: size, palatability and defence mechanisms in feeding tests, Oecologia (1990) 82, 446-449. 